\title{
Qualidade de Vida no Trabalho: Uma análise sobre o ponto de vista dos servidores públicos da Prefeitura Municipal de Capim Grosso - Bahia
}

\author{
Arlete Chagas Freire ${ }^{1}$; Juscélia Valeriana Jesus Machado Paixão ${ }^{2}$; Luzia Coelho Rodrigues ${ }^{3}$; \\ Raquel Silva Leal ${ }^{4}$; Vanessa de Paula Rosa Medeiros ${ }^{5}$
}

Resumo: O presente estudo teve como objetivo identificar, a partir da percepção dos servidores da Prefeitura Municipal de Capim Grosso - Bahia, as condições de trabalho oferecidas para a realização de um trabalho produtivo, tendo como base os fatores conceituais sobre qualidade de vida no trabalho de Walton. A pesquisa é de natureza quantitativa, caráter descritivo, onde o instrumento de coleta de dados foi um questionário composto de questões fechadas e de múltipla escolha. Os resultados da pesquisa apontam que a organização ainda não implantou um Programa de Qualidade de Vida no Trabalho, além da insatisfação com as condições de trabalho, com os direitos trabalhistas e com a remuneração, o que pode contribuir para afetar, negativamente a produção. Conclui-se que a organização pesquisada precisa investir em qualidade de vida no trabalho, com o objetivo de proporcionar motivação e satisfação dos seus servidores.

Palavras chave: Motivação, qualidade de vida no trabalho, satisfação, produtividade.

\section{Quality of Life at Work: An analysis of the point of view of public servants of the Municipality of Capim Grosso - Bahia}

\begin{abstract}
The objective of this study was to identify, from the perception of the employees of the City Hall of Capim Grosso - Bahia, the working conditions offered to perform a productive work, based on the conceptual factors on quality of life at work Of Walton. The research is quantitative in character, descriptive character, where the instrument of data collection was a questionnaire composed of closed questions and multiple choice. The results of the research indicate that the organization has not yet implemented a Quality of Work at Work Program, in addition to dissatisfaction with working conditions, labor rights and compensation, which may contribute to negatively affect production. It is concluded that the research organization needs to invest in quality of life at work, with the aim of providing motivation and satisfaction of its employees.
\end{abstract}

Key words: Motivation, quality of life at work, satisfaction, productivity.

\section{Introdução}

Esta pesquisa visa levantar informações que possibilitem obter um panorama real da Qualidade de Vida no Trabalho (QVT) de uma organização pública sob o ponto de vista dos indivíduos envolvidos.

\footnotetext{
${ }^{1}$ Bacharel em Ciências Contábeis pela Faculdade de Ciências Educacionais Capim Grosso - BA. Discente do curso Bacharelado em Administração Pública da Universidade Federal do Vale do São Francisco/SEaD. E-mail: lety_freire@ hotmail.com

2 Discente do curso Bacharelado em Administração Pública da Universidade Federal do Vale do São Francisco/SEaD. Email: klbjumachado@outlook.com

3 Mestre em Administração (UFBA), docente do curso Bacharelado em Administração Pública da SEaD/Univasf. Email: luzia.coelho@univasf.edu.br

4 Discente do curso Bacharelado em Administração Pública da Universidade Federal do Vale do São Francisco/SEaD. E-mail: raqueallealadm@gmail.com

${ }^{5}$ Bacharel em Jornalismo pela Universidade São Marcos. Discente do curso Bacharelado em Administração Pública da Universidade Federal do Vale do São Francisco/SEaD. E-mail: vanessajornalista@ hotmail.com
} 
Nas últimas décadas, a sociedade passou a se preocupar com as mudanças marcantes que têm ocorrido no mundo do trabalho. A QVT é um tema em pauta no cenário atual, dado a sua importância e influência direta na vida dos indivíduos, objetivando satisfazer as necessidades do trabalhador e melhorar as condições de trabalho.

O estudo sobre Qualidade de Vida no Trabalho é pertinente, pois identifica o nível de satisfação dos colaboradores com a organização, indicando caminhos para promover um ambiente de trabalho mais saudável e produtivo. Para garantir a qualidade de vida no trabalho, a organização deve visar não somente os fatores físicos do ambiente, mas também os fatores psicológicos de seus funcionários.

Uma organização pública deve promover metas para o desenvolvimento pessoal e profissional de seus funcionários. O primeiro passo é a implementação de programas que busquem oferecer maior qualidade de vida e que englobe fatores diversos, como promoção da saúde e segurança, desenvolvimento das capacidades humanas, integração social, entre outros. Sobre as normas de saúde, higiene e segurança no trabalho, Martinez (2016) assim se manifesta:

\footnotetext{
As normas de saúde, higiene e segurança laboral, passam, então, a ter espaço central nas relações de emprego e isso se juntou diante do fato do empregador não apenas ser responsável pela contra prestação salarial dos seus operários, mas também pela manutenção da sua higidez no decurso do vínculo contratual (MARTINEZ, 2016, p. 330).
}

Sendo assim, os gestores precisam se preocupar com as condições de trabalho oferecidas aos seus funcionários, buscando meios que influenciem positivamente nas condições e qualidade de vida de seus colaboradores. A organização pública deve investir na motivação e satisfação dos seus funcionários, como meio de maximizar a excelência da prestação dos serviços públicos.

Quanto mais satisfeito e motivado, maior será o desempenho e a produção do trabalhador. Diante do exposto, a pesquisa busca responder a seguinte questão norteadora: Qual a percepção dos servidores da Prefeitura Municipal de Capim Grosso - Bahia sobre as condições de trabalho oferecidas para a realização de um trabalho produtivo? 


\section{Justificativa}

A qualidade de vida no trabalho afeta diretamente no desempenho da empresa seja ela pública ou privada. Dessa forma, investir em qualidade de vida na organização privada significa garantir produtividade e competitividade diante de uma economia tão acirrada. Já investir em qualidade de vida nas organizações públicas contribui para a garantia da prestação de serviços públicos eficientes à sociedade, a qual espera por um atendimento rápido e satisfatório.

O servidor público está a serviço da sociedade, sendo imprescindível, portanto, dedicação e capacitação para atender a população. Um servidor público comprometido e dedicado garante uma Gestão Pública eficaz e eficiente, por isso, é necessário que o servidor tenha qualidade de vida no trabalho. Esta pesquisa se justifica porque, ao realizar análises sobre a qualidade de vida no trabalho, é possível fazer um diagnóstico organizacional para melhorar os processos de trabalhos, propondo meios que elevem a autoestima e o nível de satisfação dos funcionários.

Nesse contexto, afirma-se a importância do estudo como meio de contribuição para a aplicabilidade da qualidade de vida nas organizações, visando oferecer planos de melhoria para um ambiente de trabalho confortável e seguro. Destaca-se, ainda, sua relevância em fornecer subsídios à organização para o planejamento de condições de trabalho favoráveis ao trabalho produtivo, tendo como base o nível percebido pelos servidores.

\section{Objetivos}

Geral: Identificar, a partir da percepção dos servidores da Prefeitura Municipal de Capim Grosso - Bahia, as condições de trabalho oferecidas para a realização de um trabalho produtivo.

\section{Específicos:}

a) Verificar a existência de práticas de QVT no âmbito da Prefeitura de Capim Grosso; 
b) Identificar os fatores que influenciam na qualidade de vida dos trabalhadores;

c) Propor subsídios para a implantação do Programa de QVT na Prefeitura Municipal de Capim Grosso.

\section{A Origem da Qualidade de Vida no Trabalho}

A busca pela qualidade de vida no trabalho teve início na década de 1950, no Tavistock Institute, em Londres, com a abordagem sociotécnica, quando Eric Trist e colaboradores realizaram um estudo sobre o indivíduo, trabalho e organização, porém, só ganhou destaque na década de 1960, quando estudiosos, empresários e governo se interessaram na organização do trabalho, visando maximizar a produção, a qual dependia fortemente do bem estar dos trabalhadores. Nessa mesma época foi criada nos Estados Unidos a National Comission on Produtivity, que visava identificar os motivos da baixa produção nas empresas americanas. Contudo, o termo Qualidade de Vida no Trabalho (QVT), só foi introduzido inicialmente por Louis Davis, na década de 1970 (FROSSARD, 2009).

A qualidade de vida no trabalho, segundo descreve Rodrigues (1994, p. 76), "tem sido uma preocupação do homem desde o inicio de sua existência com outros títulos em outros contextos, mas sempre voltada para facilitar ou trazer satisfação e bem estar ao trabalhador na execução de sua tarefa". O interesse pela QVT foi reforçado pelo mundo globalizado e pela competitividade entre os mercados. Logo assim, a QVT virou motivo de interesse de diversos países.

No Brasil, o crescimento do mercado de importação e exportação, despertou nas empresas o interesse por Programas de Qualidade Total. De acordo com Chiavenato (2010, p.487) "a gestão de qualidade total nas organizações depende fundamentalmente da otimização do potencial humano. E isto depende de quão bem as pessoas se sentem trabalhando na organização".

Para alcançar o máximo da qualidade e produtividade é necessário que as organizações motivem as pessoas, fazendo com que essas participem ativamente das atividades que realizam e que sejam recompensadas de forma justa. Para definir QVT é preciso considerar o fator humano, juntamente com a melhoria do desempenho organizacional. 


\section{Conceitos sobre Qualidade de Vida no Trabalho}

A QVT atualmente é tema de vários estudos e tem interessado bastante às organizações públicas e as empresas privadas, pois, seus efeitos afetam diretamente na produtividade. De forma simples, a qualidade de vida no trabalho está relacionada ao trabalhador, ao trabalho e à organização. Porém, para conceituar QVT é necessário considerar os fatores individuais (crenças, expectativas e necessidades do profissional), e os fatores situacionais (ambiente de trabalho, recursos, tecnologia e outros), tudo isso ligado ao bemestar e saúde dos empregados, consequentemente relacionados à motivação e satisfação das pessoas no trabalho.

QVT envolve tantos aspectos físicos e ambientais como aspectos psicológicos do local de trabalho. A QVT assimila duas posições antagônicas: de um lado, a reivindicação dos colaboradores quanto ao bem-estar e satisfação no trabalho e de outro, o interesse das organizações quanto a seus efeitos potenciadores sobre a produtividade e qualidade. (Chiavenato, 2010, p.487)

Fernandes (1996) diz que a expressão Qualidade de Vida no Trabalho, abrange, além dos atos legislativos que resguardam o trabalhador, o atendimento a necessidades e anseios humanos, baseado na idéia de humanização do trabalho e na responsabilidade social da empresa.

É necessário analisar o tema de forma a valorizar a dimensão individual envolvendo seu corpo e sua saúde física e mental, a relação com as pessoas diretamente próximas (a família), com o trabalho (empregador, colegas de trabalho) e com a comunidade da qual participa. (OLIVEIRA, 2011, p. 116)

Chiavenato (2008) menciona que a qualidade de vida resulta em formar, preservar e desenvolver o local laboral. Desta forma, o ambiente laboral torna-se prazeroso e harmônico. Romero (2013) afirma que a QVT procura minimizar o excesso de força física no trabalho e o mal-estar.

Nesse sentido, para que os indivíduos tenham um bom ambiente de trabalho devem ser oferecidas boas condições de trabalho, isto é, um ambiente saudável que proporcione estabilidade psicológica, emocional e física (MENDES, 2012), ou seja, o sucesso e o pleno 
desenvolvimento das organizações dependem muito das condições de trabalho oferecidas aos funcionários. Por isso, é importante que as organizações considerem, além dos aspectos físicos do ambiente, os aspectos psicológicos e físicos dos seus funcionários. A QVT tem a capacidade de maximizar o comprometimento do funcionário para com a empresa.

Existem diversas definições para a QVT, mas de forma resumida, é um conjunto de ações que tem impacto direto na otimização e potencial humano das organizações. Assim, as organizações que desenvolvem atividades ligadas à qualidade de vida dos seus funcionários consequentemente vão influenciar positivamente no comportamento destes, principalmente nos aspectos de bem-estar, saúde, segurança, satisfação e motivação.

Chiavenato (2010) afirma que os aspectos intrínsecos e extrínsecos do cargo afetam atitudes pessoais e comportamentos fundamentais para a produtividade individual e grupal como: motivação, adaptabilidade a mudanças, criatividade e desejo de inovar ou aceitar mudanças e, sobretudo, agregar valor à organização.

\section{Motivação no trabalho}

Observa-se que no ambiente organizacional, a motivação é um dos fatores mais importante para a realização das atividades. Chiavenato (2010) reforçou essa idéia ao afirmar que o funcionário bem motivado tem mais comprometimento, mais disposição e destreza para realizar suas atividades laborais. Portanto, se as organizações buscam excelência na produtividade e na prestação de serviços por parte de seus funcionários, é necessário investir mais em programas que ofereçam maior qualidade de vida.

Proporcionar um ambiente de trabalho confortável, fisicamente falando, onde os indivíduos se sintam bem e também com um clima amistoso, onde as pessoas se relacionem de forma prazerosa com elas mesmas, com os superiores e com os demais colegas, permitem a realização pessoal e organizacional. De acordo com Davis e Newstron (1992, p.28), “o resultado de um sistema eficaz de comportamento organizacional é a motivação que, quando combinada com as habilidades e capacidades do empregado, resulta na produtividade humana". 
Maslow (1954) e Herzberg (1968) foram estudiosos clássicos, que se aprofundaram nos fatores motivacionais relacionados às necessidades humanas, ligadas no desempenho e na autorrealização do indivíduo. Abaixo figura que representa a hierarquia das necessidades humanas segundo Maslow.

Figura 1 - Pirâmide das necessidades humanas

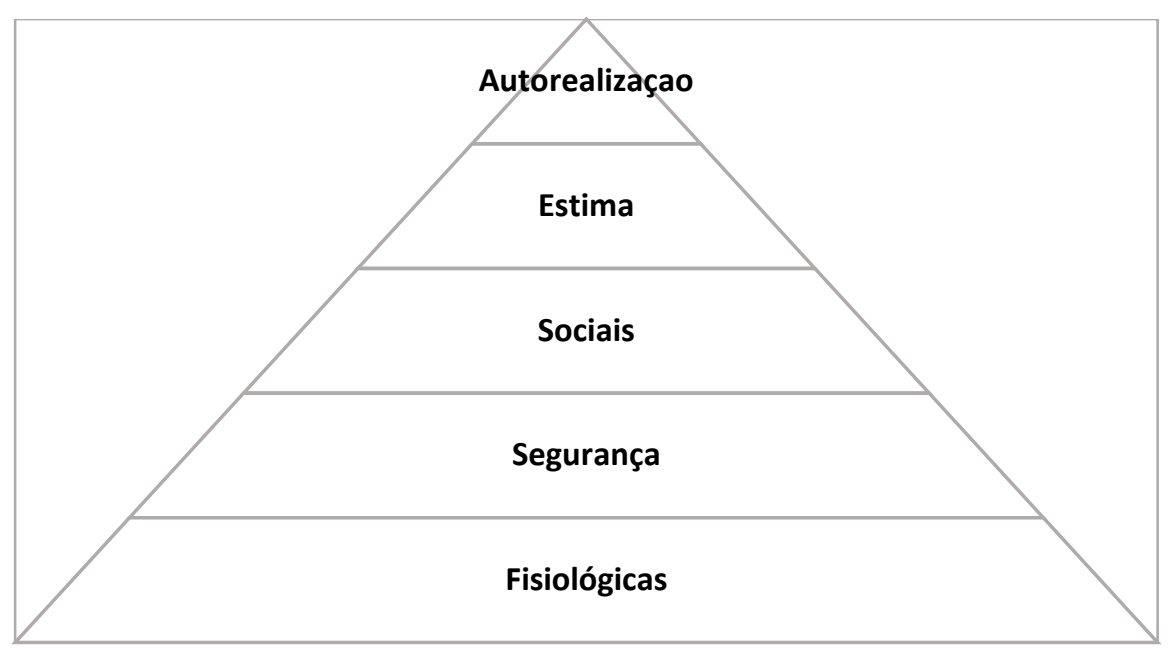

Fonte: Adaptado de Ferreira, Demutti, Gimenez (2010)

As necessidades fisiológicas significam as prioridades do organismo, como alimentação, sono, abrigo, água, excreção e outros. A necessidade de segurança representa a proteção contra a violência, proteção para saúde, recursos financeiros e outros. As necessidades sociais dependem da segurança e estão relacionadas aos seguintes fatores: amizades, socialização, aceitação em novos grupos, intimidade sexual e outros. As necessidades de estima dependem da realização das necessidades sociais e correspondem aos seguintes aspectos: status, autoconfiança, reconhecimento, conquista, respeito dos outros, confiança. Já a necessidade de autorrealização significa a busca pela individualidade e a priorização do seu potencial (FERREIRA; DEMUTTI; GIMENEZ, 2010).

As pessoas têm características pessoais próprias e diferentes, vários aspectos interferem na qualidade de vida de cada um. Na realização do serviço mesmo quando as necessidades econômicas e sociais são atendidas os funcionários devem ser motivados.

Para França (2015, p.167), "as necessidades das pessoas e os novos desafios no trabalho têm estimulado a estruturação das atividades de qualidade de vida nas empresas, 
caracterizando uma nova competência, uma nova especialização gerencial". Diante desta realidade, as empresas devem procurar se adequar as novas demandas, uma vez que o principal ponto da QVT é a valorização individual do ser humano, envolvendo diversos fatores, a exemplo de saúde, família, ambiente de trabalho e sociedade.

Segundo Walton (1973, apud CHIAVANETO, 2010, p. 489), existem oito fatores conceituais de qualidade de vida no trabalho:

a) Compensação justa e adequada - referente à remuneração recebida, onde esta deve ser suficiente para viver dignamente na sociedade a qual o empregado está inserido, devendo haver ainda equidade interna e equidade externa;

b) Condições de trabalho - caracterizada pela manutenção da saúde e do bem-estar do empregado, abrange aspectos como a jornada de trabalho, a carga horária, o ambiente físico, os materiais e equipamentos disponíveis para o serviço, as condições de saúde e segurança;

c) Uso e desenvolvimento de capacidades - são as oportunidades dadas ao empregado para aplicar suas aptidões profissionais, mediante fatores como: autonomia, autocontrole relativo, qualidades múltiplas e informação sobre o processo de trabalho;

d) Oportunidade de crescimento e segurança - são as oportunidades disponibilizadas pela organização, que permitem o crescimento pessoal dos trabalhadores, baseados na possibilidade de carreira, crescimento pessoal e segurança de emprego;

e) Integração social na organização - é marcada pela igualdade de oportunidades, pelos bons relacionamentos e convívios sociais, pelo senso comunitário, pela mobilidade e pela ausência de preconceitos;

f) Constitucionalismo - é o cumprimento dos direitos do empregado, como os direitos trabalhistas, privacidade social e liberdade de expressão;

g) O trabalho e espaço total da vida - consiste em manter um equilíbrio entre o trabalho e a vida pessoal do trabalhador;

h) Relevância social da vida no trabalho - consiste na valorização do trabalho, na responsabilidade social da organização pela comunidade e na responsabilidade social pelos serviços e pelos empregados.

França (2015, p. 173) enfatiza a importância do uso de auxílio de indicadores para a gestão de QVT: "viabilizar maior capacidade estratégica, gerencial e operacional para as questões de Qualidade de Vida no Trabalho", igualando a questão de QVT com as outras 
áreas importantes das empresas. Os indicadores refletem o nível de satisfação dos funcionários, visto que a produtividade e a qualidade de serviço dependem fortemente da motivação.

Segundo a teoria das necessidades de Maximiano (2012, p. 265), "a mais importante das explicações modernas sobre o conteúdo da motivação estabelece que as pessoas sejam motivadas essencialmente pelas necessidades humanas". Isto quer dizer, quanto maior a necessidade, maior será a motivação. Sendo assim, faz-se necessário estudar as atitudes dos funcionários, através do comportamento organizacional. Segundo os autores Davis e Newstrom (1992) é preciso analisar os seguintes elementos deste comportamento:

a) Pessoas: representam o sistema social das organizações. Eles formam grupos e equipes para fazerem o trabalho. Sem elas as organizações simplesmente não existiriam. São dinâmicas e passíveis de mudanças.

b) Estrutura: serve para representar formalmente os relacionamentos entre as pessoas nas organizações. Definem cargos, serviços, tarefas, status e etc. As estruturas são complexas e passíveis de problemas de relacionamentos.

c) Tecnologia: existe com intuito de realização do trabalho. Como as organizações não existem sem as pessoas, as pessoas necessitam de tecnologia para a realização de suas tarefas.

d) Ambiente: as corporações são afetadas pelos ambientes em que operam, e por estas são afetados também. O ambiente externo está intimamente relacionado com decisões, ameaças, oportunidades entre dezenas de situações vivenciadas no mundo empresarial.

As pessoas possuem diferentes sentimentos e criam grupos, dos quais se identificam, dentro do ambiente de trabalho, "além disso, levam para dentro da empresa praticamente todos os seus interesses como pessoas e membros de famílias ou grupos externos. Por isso é necessário ficar atento ao comportamento de cada indivíduo" (MAXIMIANO, 2012, p.223).

A cultura do indivíduo influencia o ambiente organizacional, e isso pode impactar o desempenho da empresa, sendo importante observar a conduta de cada funcionário, buscando sempre maximizar suas potencialidades em benefício da empresa. 


\section{QVT na Organização Pública}

Nos anos recentes, surgiu um significativo aumento no interesse em QVT. Apesar disso, Amorim (2010) entende que o gestor enfrenta dificuldades para implantar planos de QVT no setor público, por estar preso a leis, orçamento e questões funcionais, independentemente de perceber que práticas que melhoram a qualidade de vida no trabalho corrigem lacunas sobre aspectos de um rendimento saudável do servidor. Para tanto, as organizações devem ser mais adaptáveis, regulares e dinâmicas, promovendo, assim, transformação no vínculo entre servidores, gestor e organização.

A Administração Pública precisa buscar meios que incentivem a realização do ser humano, uma vez que este é o principal ativo de uma organização. Sendo assim, a organização pública precisa estimular as competências individuais, para o alcance de um objetivo maior que é uma prestação de serviços eficientes e de qualidade, sempre voltados para o bem coletivo e o interesse social, já que o cidadão é o centro principal da administração pública (BÚRIGO, 1997).

Surgem, então, novas práticas de gestão de pessoas alinhadas aos objetivos organizacionais, com diversas ferramentas de gestão e adoção de uma visão sistêmica, entre seus subsistemas (DUTRA, 2009), em substituição ao modelo tradicional. Isso enfatiza a importância da administração de recursos humanos para as organizações (OLIVEIRA, 2006), gestão que deve ser caracterizada pelo enfoque sistêmico, não limitando apenas a inovações tecnológicas ou a alterações em suas rotinas trabalhistas e disciplinares (GIL, 1994).

No conjunto dessas novas práticas, incluem-se as atividades voltadas para a qualidade de vida no trabalho, embora ainda incipientes no setor público. Ferreira, Alves e Tostes (2009) afirmam que no serviço público as atividades voltadas para a QVT são limitadas, quase não exploradas. Paiva e Couto (2008) reforçam dizendo que no setor público é mais difícil ocorrer transformações e as mudanças nas organizações muitas vezes, acontecem em momentos de crises.

Nesse sentido, as organizações públicas têm buscado melhorar seu desempenho, ajustando os seus objetivos com os dos funcionários, por meio de investimento em recursos intelectual e na implantação de gestão estratégica de pessoas, porém com poucas ações de 
QVT, não havendo, ainda, muita divulgação sobre a implantação desses programas no setor público (OLIVEIRA; MEDEIROS, 2011).

\section{Metodologia}

A pesquisa é de natureza quantitativa, caráter descritivo, com análise, a partir da percepção dos servidores da Prefeitura Municipal de Capim Grosso, sobre a qualidade de vida no ambiente de trabalho.

O instrumento de coleta foi composto de questões fechadas e de múltipla escolha, e foi aplicado diretamente pelos pesquisadores, no ambiente de trabalho dos respondentes. Roesch (1999) explica que, na pesquisa quantitativa, o questionário é um instrumento utilizado, podendo ser aplicado para obter informações importantes sobre opiniões, costumes, crenças, comportamentos, expectativas e preferências, portanto adequado para este estudo.

Para a elaboração do questionário, foram usados os fatores que afetam a QVT, estabelecidos por WALTON (1973). O instrumento foi aplicado, durante o período de 09 a 16 de janeiro de 2017, em todos os setores da sede da Prefeitura Municipal de Capim Grosso Bahia (Secretaria de Administração, Secretaria de Finanças, Secretaria de Obras e Urbanismo, Meio Ambiente e Turismo, e setores de Licitação e Contratos, Comunicação, Contabilidade, Guarda Municipal, Digitalização, Patrimônio, Compras, Controle Interno e Junta Militar), obtendo 30 questionários válidos, correspondentes a 50\% da população pesquisada.

Os dados coletados foram submetidos à análise com o auxílio do programa Excel.

\section{Resultados e Discussão}

Quanto ao perfil dos servidores pesquisados, o público feminino é superior a 53\%, enquanto 46,67\% são do sexo masculino. O público com nível superior completo é cerca de $30 \%$ dos respondentes, enquanto $43,34 \%$ informaram ter completado o ensino médio, sendo que $16,67 \%$ desse percentual já possuem nível superior incompleto. Cerca de $10 \%$ dos 
respondentes tem apenas o ensino fundamental ou não concluíram o ensino médio. Mais de $16 \%$ não responderam o quesito sobre a escolaridade.

\section{Percepção dos respondentes sobre fatores organizacionais}

Quanto à carga horária semanal de trabalho, mais de 70\% cumprem 40 horas, 3,33\% cumprem 50 horas, $3,33 \%$ cumpre 20 horas e $20 \%$ não responderam. A média de idade dos participantes é de 38 anos, com tempo de empresa e do atual cargo, respectivamente, de oito e seis anos.

Os dados coletados sugerem que, para ingresso na organização estudada, a formação de no mínimo nível médio é a exigência para a maioria dos cargos. A análise do tempo de empresa indica que os servidores gozam de estabilidade, fato comum no serviço público. A média de tempo no cargo atual foi acima de 4 anos, que corresponde ao tempo de gestão do governo municipal, isto significa dizer que não existe mudanças constantes de níveis de cargos.

Para a análise das condições de trabalho, a partir da percepção dos servidores, foram considerados os fatores organizacionais, ambientais e comportamentais (Walton, 1973). Os resultados encontrados acerca dos fatores organizacionais que influenciam a qualidade de vida dos servidores são os demonstrados na tabela 1 .

Tabela 1 - Percepção de servidores sobre os Fatores Organizacionais

\begin{tabular}{l|l|l|l|l|l|l}
\multicolumn{1}{c|}{ Item } & Sempre & $\begin{array}{c}\text { Quase } \\
\text { Sempre }\end{array}$ & $\begin{array}{c}\text { Às } \\
\text { Vezes }\end{array}$ & Raramente & Nunca & $\begin{array}{c}\text { Não } \\
\text { responderam }\end{array}$ \\
\hline $\begin{array}{l}\text { Integração dos funcionários } \\
\text { fora do horário de } \\
\text { expediente. }\end{array}$ & $16,67 \%$ & $3,33 \%$ & $26,67 \%$ & $26,67 \%$ & $26,67 \%$ & - \\
\hline $\begin{array}{l}\text { Investimento em Capacitação } \\
\text { Percepção de benefícios } \\
\text { extras, como assistência } \\
\text { médica, } \\
\text { creche, vale transporte }\end{array}$ & $3,33 \%$ & - & $3,33 \%$ & $10 \%$ & $83,33 \%$ & \\
\hline $\begin{array}{l}\text { Preocupação da organização } \\
\text { com a assistência à saúde no } \\
\text { ambiente de trabalho }\end{array}$ & $16,67 \%$ & $3,33 \%$ & $16,67 \%$ & $16,67 \%$ & $43,33 \%$ & $3,33 \%$ \\
\hline $\begin{array}{l}\text { A organização possibilita a } \\
\text { construção de uma carreira } \\
\text { e/ou de avanços salariais }\end{array}$ & $10 \%$ & $6,67 \%$ & $6,67 \%$ & $10 \%$ & $60 \%$ & $6,67 \%$ \\
\hline
\end{tabular}


Id on Line Revista Multidisciplinar e de Psicoloqia

Id on Line Multidisciplinary and Psycology Journal

\begin{tabular}{l|l|l|l|l|l|l}
\hline $\begin{array}{l}\text { Necessidade de realização de } \\
\text { horas extras }\end{array}$ & $26,67 \%$ & $6,67 \%$ & $36,67 \%$ & $13,33 \%$ & $13,33 \%$ & $3,33 \%$ \\
\hline $\begin{array}{l}\text { Ocorrências de promoções } \\
\text { baseadas em competência e } \\
\text { produtividade }\end{array}$ & - & $3,33 \%$ & $20 \%$ & $20 \%$ & $53,33 \%$ & $3,33 \%$ \\
\hline $\begin{array}{l}\text { Investimento na carreira } \\
\text { através da oferta de cursos ou } \\
\text { estímulo para continuidade } \\
\text { aos estudos }\end{array}$ & $6,67 \%$ & - & - & $16,67 \%$ & $76,67 \%$ & - \\
\hline $\begin{array}{l}\text { Benefícios e direitos } \\
\text { trabalhistas são respeitados } \\
\text { com frequência }\end{array}$ & $20 \%$ & $13,33 \%$ & $20 \%$ & $23,33 \%$ & $23,33 \%$ & - \\
\hline $\begin{array}{l}\text { A qualidade com a qual } \\
\text { realizo o meu trabalho pode } \\
\text { afetar a vida de muitas } \\
\text { pessoas }\end{array}$ & $36,67 \%$ & $6,67 \%$ & $13,33 \%$ & $13,33 \%$ & $30 \%$ & - \\
\hline $\begin{array}{l}\text { Possui independência e } \\
\text { liberdade para realizar o } \\
\text { trabalho }\end{array}$ & $13,33 \%$ & $23,33 \%$ & $26,67 \%$ & $13,33 \%$ & $23,33 \%$ & - \\
\hline $\begin{array}{l}\text { Sente orgulho de dizer onde } \\
\text { trabalha }\end{array}$ & $50 \%$ & $6,67 \%$ & $20 \%$ & $10 \%$ & $10 \%$ & $3,33 \%$ \\
\hline
\end{tabular}

Fonte: Dados da pesquisa (2017)

Quanto à integração social fora da organização, a pesquisa apontou que dificilmente acontecem eventos para promover a relação dos servidores. Os momentos de interação fora do local de trabalho permitem que as pessoas se conheçam melhor, geram afetividade, que consequentemente é movida para o ambiente de trabalho, favorecendo na produtividade (FROSSARD, 2009).

No quesito oportunidade de crescimento na carreira, os resultados sugerem haver insatisfação dos funcionários quanto ao investimento em capacitação, bem como é possível inferir que a organização pesquisada não possui planos de cargos, carreiras e salários que possibilitem a valorização das competências e produtividades individuais. $\mathrm{Na}$ escala de avaliação da satisfação, mais de $76 \%$ dos respondentes atribuíram indicativas da inexistência de oferta de cursos complementares ou estímulos para educação continuada, sugerindo, a partir desses achados, que a organização deve promover ações para o investimento na carreira de seus colaboradores e para potencializar a motivação no trabalho (MAXIMIANO, 2012).

A qualificação profissional é fundamental para a realização de um trabalho eficaz e eficiente. Servidores altamente qualificados aumentam a produção e se comprometem mais com suas funções, impactando positivamente a imagem da organização e contribuindo para aumentar a QVT. 
Quando o assunto é compensação justa e adequada, 83,33\% responderam que nunca receberam benefícios extras, como assistência médica, odontológica e outros, evidenciando, para os respondentes, que a organização não investe em capital humano e não utiliza outros benefícios para motivar e estimular os seus servidores.

Ainda no que se refere aos fatores organizacionais, variável remuneração pelo trabalho, infere-se, a partir da percepção dos servidores respondentes, que não há consenso quanto à adequação da remuneração pelos serviços prestados, uma vez que cerca de $50 \%$ dos respondentes avaliaram o item entre razoavelmente satisfeito a satisfeito, enquanto parte igual avalia negativamente a remuneração, conforme demonstrado na figura 2 , o que leva a crer que não há clareza, para os respondentes, quanto à associação entre remuneração justa e adequada pelos serviços prestados e qualidade de vida (WALTON, 1973; CHIAVANETO, 2010).

Figura 2 - Percepção de servidores sobre adequação da remuneração pelo trabalho

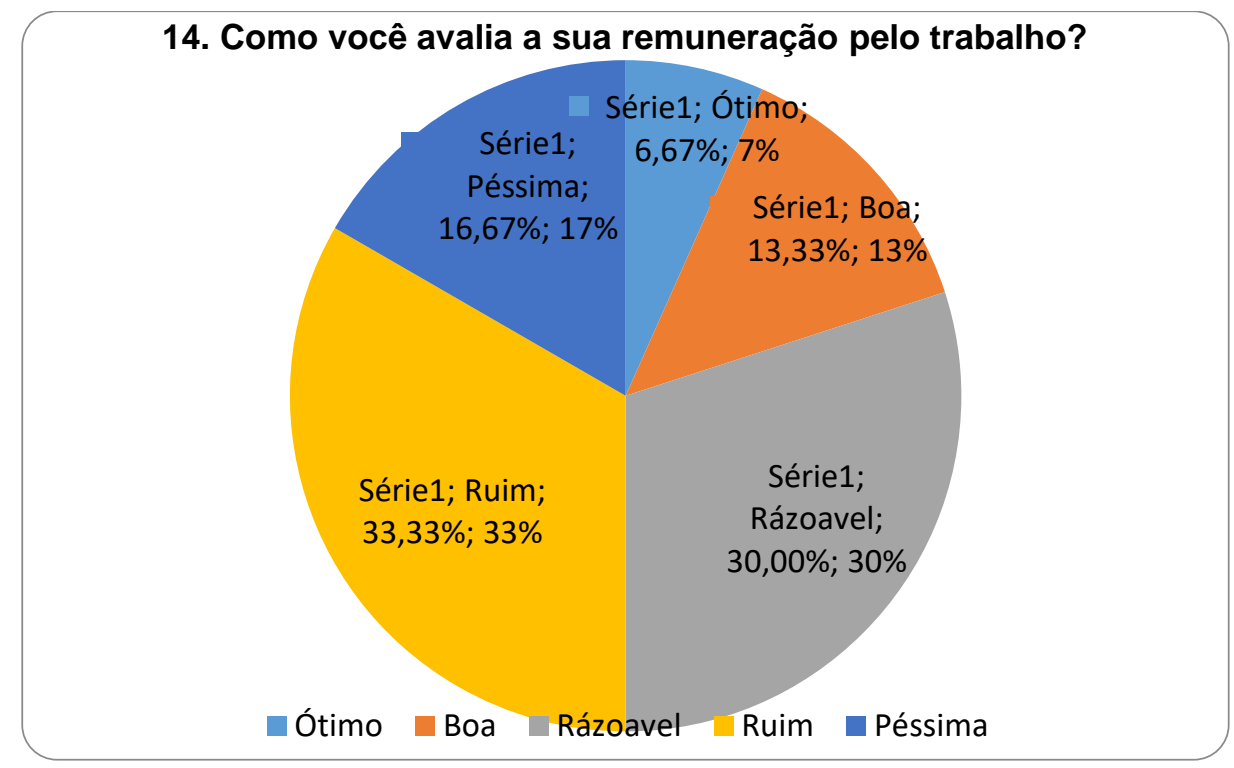

Fonte: Dados da pesquisa (2017))

No que tange as condições de trabalho, referente assistência à saúde, embora 43,33\% dos respondentes tenham avaliado negativamente o item, a maioria (53,34\%) atribuiu respostas indicativas da existência de preocupação da organização pesquisada com a assistência à saúde no ambiente de trabalho, ensejando a necessidade de implantação e ou divulgação de programas de QVT no âmbito da Prefeitura Municipal de Capim Grosso, 
convergindo para os achados na literatura sobre a pouca exploração de ações voltadas para a qualidade de vida no trabalho no setor público (FERREIRA; ALVES; TOSTES, 2009; PAIVA; COUTO, 2008; OLIVEIRA; MEDEIROS, 2011; PASSOS, 2016).

Concernente à jornada de trabalho, metade dos respondentes avalia a carga de trabalho como razoável, chegando a mais de $80 \%$ os que a consideram entre razoável e ótima. É importante relembrar que $73,33 \%$ dos respondentes disseram que cumprem 40 horas semanais, o que não resulta em sobrecarga, uma vez que, apenas, cerca de $3 \%$ admitiram que trabalham 50 horas por semana, ultrapassando a carga horária permitida, conforme demonstrado na figura 3.

Figura 3 - Percepção de servidores sobre a carga horária diária de trabalho

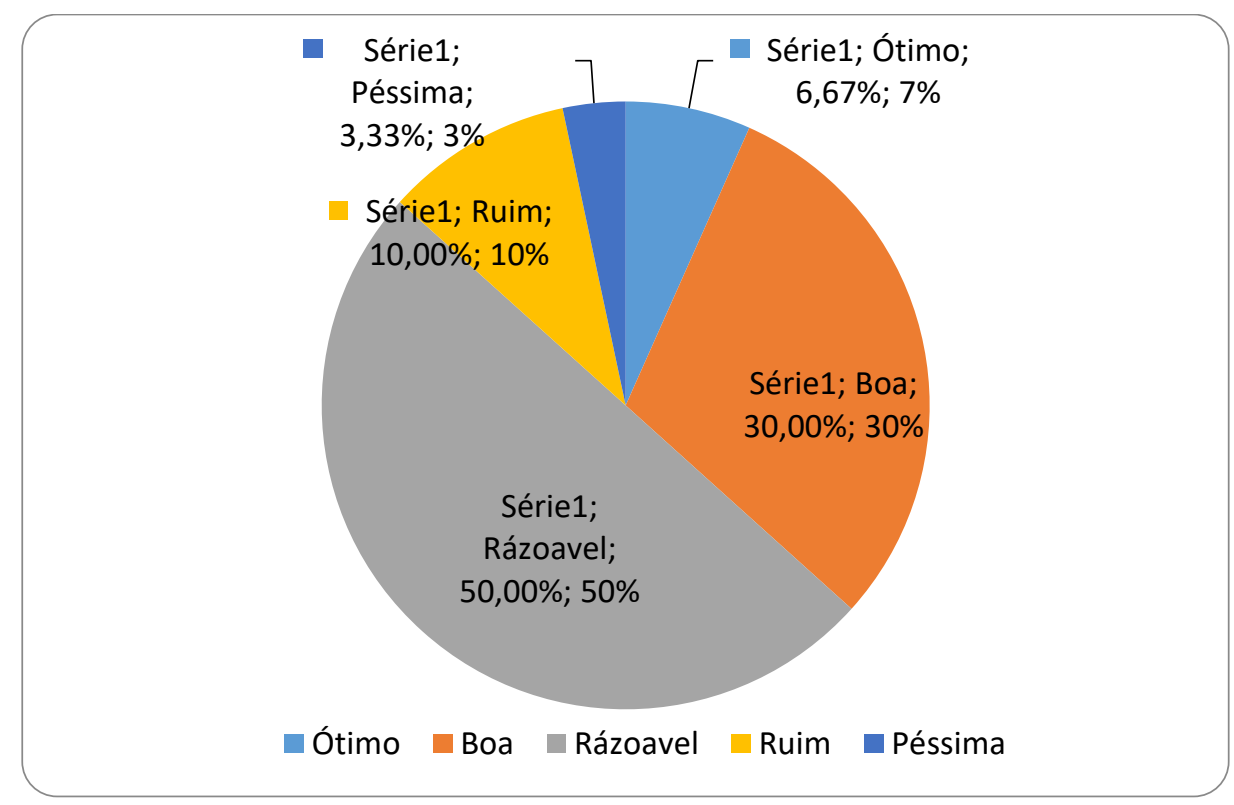

Fonte: dados da pesquisa (2017)

Em relação ao trabalho e espaço total da vida, resultados indicam desequilíbrio entre a vida social do servidor e a vida no trabalho, pois a maioria tem se dedicado a realização de horas extras, sugerindo refletir sobre jornada de trabalho que não prejudique a vida social, evitando, assim, impactar, negativamente, a Qualidade de Vida do servidor.

No que tange ao constitucionalismo, pode ser verificado na tabela 1 que $23,33 \%$ dos pesquisados declararam que raramente seus benefícios e direitos trabalhistas são respeitados, percentual igual para os que optaram pela alternativa sinalizada pelo termo "nunca". Essa 
declaração instiga o desejo de saber exatamente quais direitos não estão sendo respeitados, uma vez que mais de $50 \%$ atribuíram respostas acima do ponto médio da escala, resposta que não pode ser obtida com as questões fechadas.

Quanto ao uso e desenvolvimento de capacidades, mais de $36 \%$ avaliam positivamente o quesito, somado aos que, "às vezes", possuem independência e liberdade no trabalho (26,67\%), observa-se que mais de $60 \%$ dos servidores são beneficiados com essa autonomia. No entanto, 23,33\% dos participantes informam que nunca possuem independência e liberdade, sugerindo o desdobramento do estudo no sentido de verificar se há concentração dessa insatisfação em determinado setor da organização ou se acontece de forma isolada em todos os setores. Vale ressaltar a importância da aplicação, pelo servidor, de saberes, habilidades e capacidades individuais e aptidões profissionais, contribuindo para aumentar o nível de satisfação pessoal e a qualidade de vida no trabalho (FERREIRA; ALVES; TOSTES, 2009; PAIVA; COUTO, 2008; OLIVEIRA; MEDEIROS, 2011; PASSOS, 2016).

É possível inferir, a partir da percepção dos servidores, que há insatisfação de usuários em relação às variáveis referentes à capacitação de servidores, concessão de benefícios extras e desenvolvimento na carreira, todas pertencentes aos fatores organizacionais, porém, no que se refere à relevância social de vida no trabalho, a maioria dos respondentes afirmou sentir orgulho de pertencer à instituição, variável importante para a construção da imagem organizacional perante a sociedade.

A percepção de servidores sobre os fatores ambientais está demonstrada na tabela 2 , com questões que estão ligadas com as condições de trabalho.

Depreende-se, da análise da tabela 2, que mais de $60 \%$ dos respondentes entendem que fatores ambientais, tais como calor, poeira e ruído estão impactando negativamente no seu bem-estar, percentual aproximado aos que avaliam não ter suas necessidades fisiológicas básicas atendidas de forma adequada. Contudo, utilizando a mesma escala avaliativa para a segurança e as condições de trabalho, os itens não recebem avaliação negativa, divergindo da avaliação para os itens: espaço físico e recursos materiais para a execução da função, os quais foram negativamente avaliados pelos respondentes. 
Id on Line Revista Multidisciplinar e de Psicoloqia

Id on Line Multidisciplinary and Psycology Journal

Tabela 2 - Percepção de servidores sobre os Fatores Ambientais

\begin{tabular}{|c|c|c|c|c|c|c|}
\hline Item & Sempre & $\begin{array}{l}\text { Quase } \\
\text { Sempre }\end{array}$ & $\begin{array}{c}\text { Às } \\
\text { Vezes }\end{array}$ & Raramente & Nunca & $\begin{array}{c}\text { Não } \\
\text { responderam }\end{array}$ \\
\hline $\begin{array}{l}\text { A poeira, o ruído e o calor } \\
\text { causam-lhe mal estar, } \\
\text { prejudicando sua saúde? }\end{array}$ & $30 \%$ & $6,67 \%$ & $30 \%$ & $16,67 \%$ & $16,67 \%$ & - \\
\hline $\begin{array}{l}\text { Suas necessidades fisiológicas } \\
\text { básicas são satisfeitas } \\
\text { adequadamente? }\end{array}$ & $40 \%$ & $10 \%$ & $10 \%$ & $26,67 \%$ & $13,33 \%$ & - \\
\hline Item & Ótima & Boa & Razoável & Ruim & Péssima & $\begin{array}{c}\text { Não } \\
\text { responderam }\end{array}$ \\
\hline $\begin{array}{l}\text { Como você avalia a segurança } \\
\text { no ambiente de trabalho? }\end{array}$ & $6,67 \%$ & $33,33 \%$ & $30 \%$ & $16,67 \%$ & $13,33 \%$ & - \\
\hline $\begin{array}{l}\text { Como você classifica as } \\
\text { condições ambientais de } \\
\text { trabalho (iluminação, higiene, } \\
\text { ventilação e organização)? }\end{array}$ & $6,67 \%$ & $23,33 \%$ & $33,33 \%$ & $16,67 \%$ & $20 \%$ & - \\
\hline $\begin{array}{l}\text { Como você classifica os } \\
\text { recursos materiais, } \\
\text { necessários, oferecidos para a } \\
\text { execução de sua função? }\end{array}$ & $3,33 \%$ & $20 \%$ & $50 \%$ & $10 \%$ & $16,67 \%$ & - \\
\hline $\begin{array}{l}\text { Como você classifica o espaço } \\
\text { físico disponível para a } \\
\text { execução de sua função? }\end{array}$ & $3,33 \%$ & $6,67 \%$ & $33,33 \%$ & $30 \%$ & $26,67 \%$ & - \\
\hline
\end{tabular}

Fonte: Dados da pesquisa (2017)

Os dados encontrados sugerem a necessidade de investimentos em práticas organizacionais que considerem a importância dos fatores ambientais para a manutenção da qualidade de vida no trabalho.

Tabela 3 - Percepção de servidores sobre os Fatores Comportamentais

\begin{tabular}{|c|c|c|c|c|c|c|}
\hline Item & Ótima & Boa & Razoável & Ruim & Péssima & $\begin{array}{c}\text { Não } \\
\text { responderam }\end{array}$ \\
\hline $\begin{array}{l}\text { A relação entre os colegas } \\
\text { no seu setor pode ser } \\
\text { considerada? }\end{array}$ & $30 \%$ & $66,67 \%$ & - & $3,33 \%$ & - & - \\
\hline $\begin{array}{l}\text { Como você classifica o seu } \\
\text { relacionamento com o seu } \\
\text { superior? }\end{array}$ & $36,67 \%$ & $46,67 \%$ & $13,33 \%$ & - & $3,33 \%$ & - \\
\hline $\begin{array}{l}\text { Como você classifica o } \\
\text { relacionamento dos seus } \\
\text { colegas com o seu superior? }\end{array}$ & $13,33 \%$ & $53,33 \%$ & $33,33 \%$ & - & - & - \\
\hline Item & Sempre & $\begin{array}{l}\text { Quase } \\
\text { Sempre }\end{array}$ & Às Vezes & Raramente & Nunca & $\begin{array}{c}\text { Não } \\
\text { responderam }\end{array}$ \\
\hline $\begin{array}{l}\text { Os servidores são tratados de } \\
\text { forma igual, sem } \\
\text { favoritismo? }\end{array}$ & $20 \%$ & $6,67 \%$ & $13,33 \%$ & $20 \%$ & $36,67 \%$ & $3,33 \%$ \\
\hline Com que frequência você & -- & - & $16,67 \%$ & $63,33 \%$ & $20 \%$ & - \\
\hline
\end{tabular}


Id on Line Revista Multidisciplinar e de Psicoloqia

Id on Line Multidisciplinary and Psycology Journal

\begin{tabular}{l|l|l|l|l|l|l}
\hline $\begin{array}{l}\text { falta ao trabalho por motivo } \\
\text { de doença? }\end{array}$ & & & & & & \\
\hline $\begin{array}{l}\text { Com que frequência você } \\
\text { fica doente devido ao seu } \\
\text { trabalho? }\end{array}$ & - & $3,33 \%$ & $20 \%$ & $33,33 \%$ & $40 \%$ & $3,33 \%$ \\
\hline $\begin{array}{l}\text { Com que frequência seus } \\
\text { colegas e superior ficam } \\
\text { doentes? }\end{array}$ & - & $6,67 \%$ & $20 \%$ & $63,33 \%$ & $6,67 \%$ & $3,33 \%$ \\
\hline $\begin{array}{l}\text { Com que frequência você } \\
\text { pensa em mudar } \\
\text { radicalmente de emprego? }\end{array}$ & $13,33 \%$ & $13,33 \%$ & $40 \%$ & $6,67 \%$ & $26,67 \%$ & - \\
\hline
\end{tabular}

Fonte: Dados da pesquisa (2017)

A partir da análise sobre fatores comportamentais, conforme tabela 3, mais de $60 \%$ dos respondentes afirmam tem bom relacionamento os colegas de trabalho, incluindo os cargos de chefia, sugerindo a existência de integração social entre os servidores. No entanto, $20 \%$ dos respondentes entenderam que existe tratamento diferenciado, entre os servidores, permitindo privilégios para alguns.

Figura 4 - Percepção de servidores sobre a satisfação da qualidade vida no trabalho

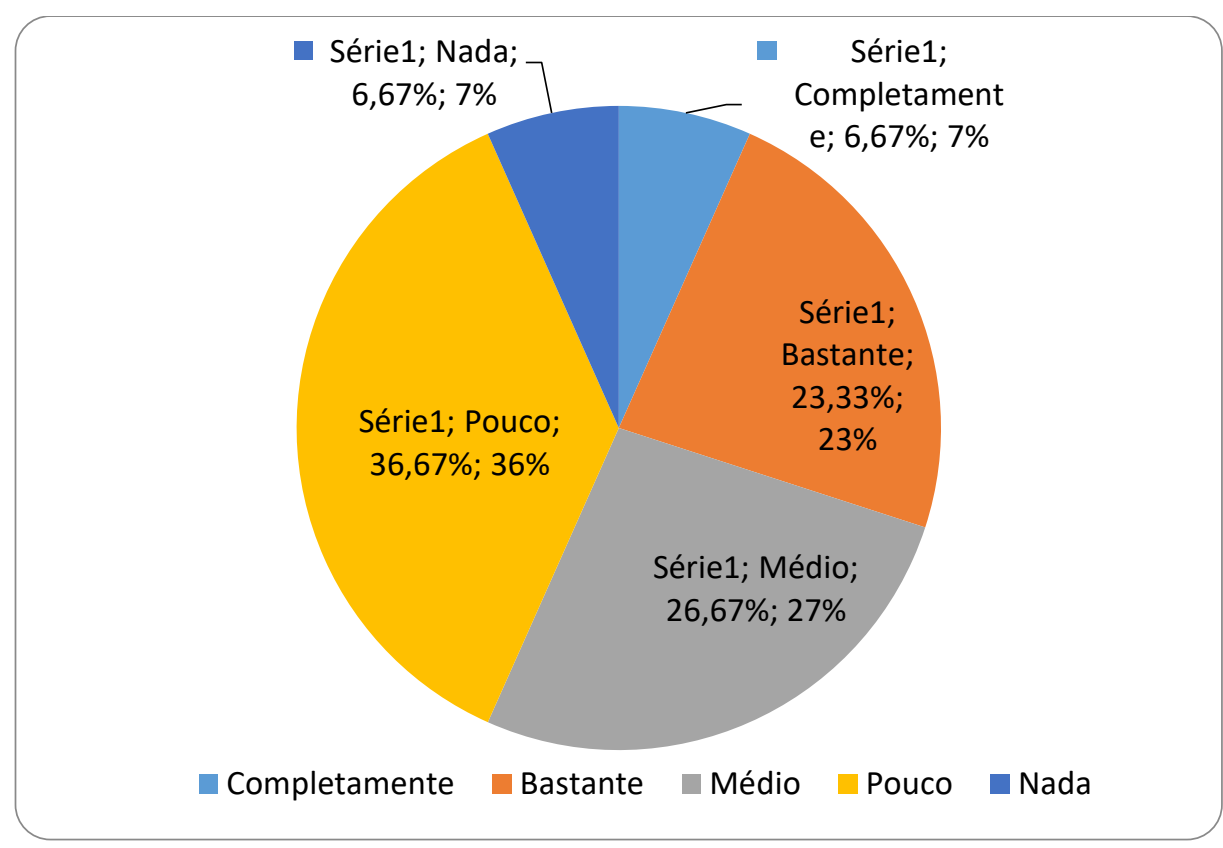

Fonte: Dados da pesquisa (2017)

Apesar dos respondentes estarem insatisfeitos com os fatores ambientais (tabela 2) que influenciam diretamente na saúde do servidor, fica evidente com os resultados dos fatores 
comportamentais (tabela 3), que dificilmente as pessoas adoecem ou falta o trabalho por motivo de doença.

A relevância social do trabalho, abordada pela necessidade de mudar de emprego demonstra que mais de $40 \%$ dos respondentes já pensaram nessa possibilidade. Nesse sentido, resultados sugerem insatisfação com a Qualidade de Vida no Trabalho, situação que pode refletir, negativamente, na excelência da prestação dos serviços públicos.

\section{Considerações Finais}

Esta pesquisa buscou identificar, a partir da percepção dos servidores da Prefeitura Municipal de Capim Grosso - Bahia, as condições de trabalho oferecidas para a realização de um trabalho produtivo, priorizando a qualidade de vida no trabalho e os fatores que afetam diretamente no desempenho dos servidores. Após a análise dos fatores foram encontrados resultados que possibilitaram avaliar o nível de satisfação dos colaboradores com a organização.

Verificou-se que a organização ainda não implantou um Programa de Qualidade de Vida no Trabalho. A análise, a partir da percepção dos servidores, sugere a existência de insatisfação com as condições de trabalho, o que pode contribuir para afetar, negativamente, a produção. Outro ponto de destaque é o desagrado com os direitos trabalhistas, a remuneração e a confirmação de favorecimento, fato que pode ter relação com a inexistência de plano de carreira, cargos e salários.

No entanto, em relação aos fatores comportamentais, variáveis como relacionamento entre as pessoas na organização surgem com avaliação positiva, sugestiva de satisfação e do sentimento de pertencimento, uma vez que os respondentes afirmam sentir orgulho de dizer onde trabalham. Esse resultado pode estar associado à responsabilidade social da organização, visto que o governo municipal oferece serviços essenciais à comunidade. Assim, a qualidade dos serviços prestados impacta na valorização e participação da organização.

Como subsídio de melhoria, sugere-se, primeiramente, a implantação de um programa de QVT e a criação de plano de carreira, o investimento em cursos de capacitação e qualificação e a implantação de melhorias das condições de trabalho. Contudo, é importante 
que seja realizada consulta sobre as necessidades dos servidores, a fim de lhes proporcionar autonomia na realização das atividades e, consequentemente, ofertar serviços de qualidade à população.

Por fim, a organização pesquisada precisa investir em qualidade de vida no trabalho, com o objetivo de proporcionar motivação e satisfação dos seus servidores.

\section{Referencias}

AMORIM, T. G. F. N. Qualidade de Vida no Trabalho: preocupação também para servidores públicos? Revista Eletrônica de Ciências Administrativas. Campo Largo, v. 9, n.1, 35-48, 2010.

BRASIL. Lei $\mathrm{n}^{\mathrm{o}}$ 10.406, de 10 de janeiro de 2002. Disponível em: <http://www.planalto.gov.br/ccivil_03/leis/2002/L10406.htm>. Acesso em $25 \mathrm{de}$ fev. de 2017.

BÚRIGO, Carla Cristina Dutra. Qualidade de vida no trabalho. Revista de Ciências Humanas. v. 15, n. 22, p. 90-111, Florianópolis/SC: ed. UFSC, $2^{\circ}$ sem, 1997.

CHIAVENATO, Idalberto. Gestão de Pessoas. 3. ed. Campus: Elsevier, 2008.

Gestão de Pessoas: o novo papel de recursos humanos nas organizações. 3.ed. Rio de Janeiro: Elsevier, 2010.

DAVIS, K. e NEWSTROM, J. W. Comportamento humano no trabalho - Uma abordagem psicológica. São Paulo: Pioneira, 1992.

DUTRA, Joel Souza. Gestão de Pessoas: modelo, processos, tendências e perspectivas. 7 ed. São Paulo: Atlas, 2009.

FERNANDES, Eda Conte. Qualidade de Vida no Trabalho. Salvador: Casa da Qualidade, 1996.

FERREIRA, André; DEMUTTI, Carolina Medeiros; GIMENEZ, Paulo Eduardo Oliveira. A Teoria das Necessidades de Maslow: A influência do Nível Educacional Sobre a sua Percepção no Ambiente de Trabalho. XIII SEMEAD, Seminário em Administração, São Paulo, p. 2-17, set. 2010.

FERREIRA, Mário César; ALVES, Luciana; TOSTES, Natalia. Gestão de Qualidade de Vida no Trabalho (QVT) no Serviço Público Federal: O Descompasso entre Problemas e Práticas Gerenciais. Psicologia: Teoria e Pesquisa, Brasília, v. 25, n. 3, p. 319-327, Jul-Set 
2009. Disponível em: <http://www.scielo.br/pdf/ptp/v25n3/a05v25n3.pdf>. Acesso em 26 de jun. de 2017.

FRANÇA, A. C. L. Prática de Recursos Humanos - PRH: conceitos, ferramentas e procedimentos. 1. ed. - 13. reimpr. São Paulo: Atlas, 2015.

FROSSARD, Maiby Carestiato. Qualidade de Vida no Serviço Público - Um Programa para a Agência Nacional do Petróleo, as Natural e Biocombustiveis - ANP. 2009. 140 f. Dissertação (Mestrado em Administração Pública) - Escola Brasileira de Administração Púbica e de Empresa, Fundação Getulio Vargas, Rio de Janeiro. 2009.

GIL, A.C. Administração de recursos humanos: um enfoque profissional. São Paulo: Atlas, 1994.

MARTINEZ, Luciano. Curso de Direito do Trabalho: Relações Individuais, Sindicais e Coletivas do Trabalho, - 7 . ed. - São Paulo : Saraiva 2016.

MAXIMIANO, A. C. A. Teoria geral da administração: da revolução urbana à revolução digital. 7. ed. São Paulo: Atlas, 2012.

MENDES, Ricardo Alves; LEITE, Neiva. Ginástica Laboral: Princípios e aplicações práticas. 3. ed. ver. e ampl. Barueri, SP: Manole, 2012.

OLIVEIRA, Alizandra Cristina. Qualidade de vida no trabalho segundo o modelo de Walton: um estudo de caso à percepção dos funcionários da Imperador Calçados. 91 f. TCC (Trabalho de Conclusão de Curso) - Universidade do Vale do Itajaí, 2006.

OLIVEIRA, José Arimatés de; MEDEIROS, Maria da Penha Machado de. Gestão de pessoas no setor público. - Florianópolis: Departamento de Ciências da Administração/UFSC; [Brasília]: CAPES : UAB, 2011.184p.

PAIVA, K. C. M.; COUTO, J. H. Qualidade de vida e estresse gerencial "pós-choque de gestão": o caso da Copasa-MG. Revista de Administração Pública, Rio de Janeiro, v. 42, n. 6, nov./dez. 2008, p. 1189 - 1211. Disponível em:〈http://www.scielo.br/pdf/rap/v42n6/08.pdf >. Acesso em: 14 nov. 2016.

PASSOS, Maria D'Ajuda Costa. Qualidade de Vida no Trabalho: Um Estudo entre Técnicos Administrativos de Duas Instituições Federais de Ensino. 2016. 147 f. Dissertação (Mestrado em Administração) - Universidade Federal da Bahia, Salvador. 2016.

RODRIGUES, M. V. C. Qualidade de vida no trabalho - Evolução e Análise no Nível Gerencial. Rio de Janeiro: Vozes, 1994.

ROESCH, S. M. A. Projetos de Estágio e de Pesquisa em Administração: guia para estágios, trabalhos de conclusão, dissertações e estudos de caso. 2. ed. São Paulo: Atlas, 1999. 
ROMERO, Sonia Mara Thater; COSTA E SILVA, Selma França; KORPS, Lucia Maria. Gestão de Pessoas: conceitos e estratégias. Curitiba: Inter Saberes, 2013.

Universidade Federal do Vale do São Francisco. Manual de Normatização de Trabalhos Acadêmicos da UNIVASF. 2. ed. Petrolina, 2013.

\section{Como citar este artigo (Formato ABNT):}

FREIRE, A.C.; PAIXÃO, Juscélia V.J.M.; RODRIGUES, Luzia C.; LEAL, rauel S.; MEDEIROS, V.P.R. Qualidade de Vida no Trabalho: Uma análise sobre o ponto de vista dos servidores públicos da Prefeitura Municipal de Capim Grosso - Bahia. Id on Line Revista Multidisciplinar e de Psicologia, Julho de 2017, vol.11, n.36, p.363-384. ISSN: 1981-1179.

Recebido: 19.07.2017

Aceito: 21.07.2017 